\title{
LA MATERNIDAD Y LOS MEDIOS MASIVOS DE COMUNICACIÓN. UN ANÁLISIS DE ARTÍCULOS PERIODÍSTICOS Y DE PROPAGANDA COMERCIAL EN COSTA RICA
}

\author{
M.Sc Blanca Valladares Mendoza \\ Profesora Investigadora \\ Instituto de Investigaciones Psicológicas \\ Universidad de Costa Rica
}

\begin{abstract}
RESUMEN
El presente artículo estudia la influencia que ejercen los medios masivos de comunicación, en la conformación de los mitos, significados y valores que se le atribuyen a la función maternal. Los resultados obtenidos confirman la influencia de los medios de comunicación como agentes socializadores de gran impacto y eficacia para mantener y reproducir la ideología de los sexos en nuestra cultura.

Descriptores: Mujeres. Maternidad. Prensa escrita. Propaganda comercial. Costa Rica. Siglo XX.
\end{abstract}

\section{INTRODUCCIÓN}

El aporte del presente artículo es producto de dos investigaciones que se enmarcan dentro de la línea de estudio sobre la maternidad y los medios comunicación, las cuales se iniciaron con el proyecto "Los significados de la Maternidad en la Prensa Escrita", y luego con el proyecto "La Maternidad en la publicidad televisiva de Costa Rica", los cuales fuerron realizados con el auspicio del Instituto de Investigaciones Psicológicas y el financiamiento de la Vicerrectoría de Investigación de la Universidad de Costa Rica. 
Los resultados de estas investigaciones muestran la gran influencia que ejerce la socialización como uno de los principales mecanismos reproductores de la ideología de los sexos en nuestra cultura. En esta reproducción, juega un papel preponderante instituciones como la familia, la educación, la religión y en general los llamados agentes de socialización, entre los cuales destacan los medios masivos de comunicación, por la gran influencia que ejercen como instancias socializadoras de gran impacto que alcanzan grandes públicos.

\section{MARCO TEÓRICO}

\section{La Maternidad en nuestra cultura}

Marcela Lagarde (1993) define la maternidad como:

“...el conjunto de hechos de la reproducción social y cultural, por medio del cual las mujeres crean y cuidan, generan y revitalizan, de manera personal, directa y permanentemente durante toda la vida a los otros, en su sobrevivencia cotidiana y en la muerte. La maternidad es sintetizada en el ser social y en las relaciones que establecen las mujeres aun cuando estas no sean percibidas a través de la ideología de la maternidad como maternales..." (Lagarde 1993: 248).

A través del maternaje y el maternazgo, la función de la maternidad está íntimamente ligada a la reproducción de la sociedad y la cultura. Mediante la maternidad, las mujeres son trasmisoras de las reglas necesarias para la vida en sociedad; en un nivel se refiere a la reproducción de seres humanos y en otro nivel a los patrones culturales, de género como categoría social (Camacho 1997: 34). Según Lagarde (1994), “...la maternidad implica la realización de tareas por amor, por obligación terrena o divina, o por instinto maternal...” 
(Lagarde 1994: 21), creencias y mitos que las mujeres han introyectado para cumplir funciones que las realiza como naturales y que por lo tanto no son reconocidos ni valorados.

Existen contradicciones al tratar la función materna, al mismo tiempo que se la idealiza glorifica y enaltece, a través de la poesía, la pintura, homenajes, día especial para celebraciones como el día de la madre, las mujeres son sujetas de tabúes, embarazos obligatorios, de marginación y subordinación.

Nuestra sociedad patriarcal exalta la maternidad como ideal femenino, le otorga poder a la mujer madre, sin embargo al considerar esta función como parte de la naturaleza femenina, las necesidades de la mujer son ignoradas, se la relega al ámbito doméstico y a una posición de subordinación. El comprender que la maternidad es una construcción social, y no un mero hecho biológico permitirá concebirla en otra dimensión, y otorgarle una justa valoración.

Por otro lado, en el cumplimiento de las demandas de la tarea maternal las madres desarrollan estrategias de protección de cuido y entrenamiento, y de esta necesidad de pensar y actuar surge una disciplina propia que la madre posee. Esto ha dado lugar a otorgar características especiales a las madres como el cuidado, la responsabilidad, la sensibilidad, la intuición, como atributos propios de su "naturaleza o esencia femenina".

Durante siglos, ha predominado una cultura sexista y discriminatoria hacia la mujer, propiciando que la subordinación de ésta no se perciba como una hecho cultural impuesto y modificable, sino como un orden natural y por lo mismo incuestionable. Aún en la actualidad, a la mujer todavía se le define no por su condición de individuo integral, sino por su condición reproductora (Bustos 1983: 16). 


\section{La función maternal en los medios de comunicación}

La construcción ideológica del ser madre es una práctica reforzada por aparatos ideológicos como la educación, la religión, la familia y los medios de comunicación entre otros. Los medios de comunicación por su inmediatez, flexibilidad y capacidad de abarcar grandes públicos, son instancias privilegiadas para crear, recrear, reproducir y difundir determinada o determinadas visiones del ser y del quehacer femenino, y también para introducir diversas propuestas de mujer en el escenario social (Charles 1993: 358).

El hecho de que los mensajes sean enviados en forma simultánea a públicos masivos, hace que sus contenidos generen pláticas, discusiones y comentarios que resignifican lo visto, leído y escuchado. Al relacionarlo con otra información, enriquece el punto de vista, genera intercambios y práctica comunicativa.

Por lo general, las mujeres entretejen la recepción de mensajes con sus obligaciones cotidianas. Leslie Steeves (1987) plantea que las mujeres usan los medios de comunicación de forma múltiples y diversas,

"...como descanso emocional a través de la identificación con los problemas de otras personas, como escape al insertarse en formas de vida mejores y más fáciles, como compañía que alivia la soledad en que vive la mujer, para obtener información práctica para solucionar los problemas cotidianos, como entretenimiento o forma de relajación..." (Steeves 1987: 58).

De esta actitud y de la realidad de las mujeres, dependerá el grado de incidencia de la propuesta de mujer trasmitida en los mensajes, que para ser aceptados retoman la moral social dominante, el sentido común, la sabiduría popular. 
Es importante hacer manifiesta las huellas que dejan los medios masivos de comunicación en la subjetividad femenina, en la concepción que tiene la mujer de su "ser" femenino, ya que la identidad femenina se encuentra condicionada a un conjunto de significaciones y concepciones impuestas en forma invisible y sutil (Bustos 1983: 14). Según Bustos (1988), se construye la subjetividad de las mujeres en función del cuido y el servicio a los otros, es por ello es que a través de la maternidad la mujer interioriza los atributos adscritos a esta función y los trasfiere también a su condición femenina (Bustos 1988: 54).

A través de la identificación mujer $=$ madre, los atributos adscritos a la maternidad son transferidos a la mujer, de esta forma, actitudes como la tolerancia, paciencia, generosidad, renuncia, entrega, bondad, dedicación, los cuales son los atributos del "ideal maternal" que resultan ser características de la feminidad.

La educación, la información y la influencia ideológica que recibe la mujer, la condicionan para buscar en el matrimonio y la maternidad su principal realización personal (Valladares 1997: 85), cualquier actividad que realice como trabajo remunerado, política, arte, docencia, se considera secundaria, substituta temporal o preparatoria para su papel central.

Los medios de comunicación masiva reflejan formas y normas de conducta culturalmente heredadas y adquiridas, que se internalisan en las mujeres y reproducen la estructura social. La ideología se trasmite a través de mensajes que parten de una concepción de lo femenino o de lo que se cree propio de la mentalidad femenina (García 1993: 379).

Los medios, también asumen una función manipuladora en el sentido de crear una conciencia falsa, sin embargo, 
"...desde lo banal hasta lo más trascendental contiene los principios y valores del grupo dominante. Es de esta forma que mantienen un status quo obedeciendo a los intereses de la clase dominante y constituyen un arma poderosa para trasmitir y mantener una ideología que convenga a sus intereses..." (Mattelart 1986: 77).

Las representaciones sobre la maternidad que difunden los medios masivos de comunicación, operan como un espacio transmisor de experiencias, significaciones, a partir de códigos que se aprenden en la vida social y que se construyen como un saber cotidiano, que no es personal, sino constituido por la generalidad de las experiencias de generaciones anteriores. De esta forma, el impacto de los medios masivos de comunicación nos remite a los significados culturales de la maternidad, al conjunto de modelos, normas, prescripciones valores, creencias, mitos que se construyen alrededor de la función maternal. Estos medios trasmiten y perpetúan una serie de prácticas y estereotipos relativos a la función maternal, asímismo ejercen una notable influencia en el modelaje del comportamiento de la mujer madre.

\section{METODOLOGÍA}

Para el análisis de los datos de las dos investigaciones: "La Maternidad en la Prensa Escrita" y "La Maternidad en la publicidad televisiva de Costa Rica", se utilizó una metodología cualitativa con enfoque de género. La muestra en ambas investigaciones se recopiló en la primera quincena del mes de Agosto, o sea en la quincena previa al día 15 de agosto, que es la celebración del "Día de la Madre” en Costa Rica. 
En el caso de la prensa escrita, la recopilación de los artículos se hizo durante los años de 1992 a 1996, y en cuanto a la propaganda comercial televisiva, la recolección se realizó en agosto de 1999. La recolección de los datos se realizó mediante grabación de los mensajes televisivos trasmitidos por la televisión local de Costa Rica, a través del sistema VHS de grabación directa. La recopilación de los artículos periodísticos se realizó en hemerotecas y bibliotecas de los dos principales diarios de Costa Rica: La Nación y La República y la Revista Perfil.

Para desarrollar los objetivos planteados y analizar el contenido ideológico de los mensajes publicitarios, se utilizó un tipo de análisis de contenido, "...el cual se centra en la significación social de los mensajes..." (Verón 1971). Es decir, los esfuerzos del análisis de contenido están dirigidos a descubrir los significados latentes de los mensajes televisivos que trasmite la propaganda comercial local, y de los artículos periodísticos de la prensa escrita con ocasión de la celebración del "Día de la Madre".

\section{OBJETIVOS GENERALES}

1. Analizar el contenido ideológico de los mensajes publicitarios referidos al tema de la maternidad, transmitidos por la televisión local de Costa Rica, durante la quincena previa al 15 de Agosto, día en que se celebra el "Día de la Madre".

2. Analizar desde una perspectiva de género, publicaciones periodísticas, artículos, noticias, entrevistas, mensajes publicitarios referidos al tema de la maternidad, los cuales fueron publicados en los periódicos: La Nación, La República y la Revista Perfil. Los 
artículos recopilados se tomaron de publicaciones sobre el "Día de la Madre", durante la primera quincena del mes de Agosto de los años 1992- 1993- 1994- 1995 y 1996.

\section{ANÁLISIS DE LOS MENSAJES PUBLICITARIOS TELEVISIVOS}

Para efectos del presente artículo, se escogieron cuatro mensajes publicitarios televisivos, de una muestra total de 29 mensajes que se recopilaron..

\section{MENSAJE PUBLICITARIO 1:}

Oster: (Canal 4, 3/8/1999, 1:32 p.m.)

\section{Observaciones:}

El mensaje se desarrolla dentro de una casa, está la madre realizando su tareas de maternaje. Con una canción de fondo se muestra a una madre bañando a su hija.

Texto: La canción dice: "Sus manos te enseñaron las caricias, sus ojos te enseñaron el amor, a ella que por ti todo lo entrega, regálale cariño, regálale Oster”.

“El regalo para mamá este 15 de Agosto es doble: por la compra de un electrodoméstico se le regala otro".

Imágenes: Diferentes electrodomésticos (licuadoras, batidoras, etc.). Toda la ambientación del comercial es de colores claros predominando el blanco.

Estereotipo femenino: Mujer madre ama de casa.

Significados que se le atribuyen a la maternidad: Amor incondicional, entrega total, abnegación. La maternidad se encuentra ligada a la pureza. 
Mitos acerca de la maternidad: Maternidad función "natural". Amor incondicional de la madre.

Roles y prácticas adscritas a la maternidad: Cuido y atención de los hijos, ama de casa dedicada a quehaceres domésticos.

\section{MENSAJE PUBLICITARIO 2:}

Siropes La Mundial (Canal 4, 3/8/1999, 2:13 p.m.)

\section{Observaciones:}

La Mundial, para el día de la madre promociona el regalo de cocinas, hornos de microondas, batidora y cinco canastas con el producto.

Texto: "El regalo perfecto para el día de la madre".

Imágenes: Electrodomésticos, flores.

Estereotipo femenino: Mujer ama de casa.

Significados de la maternidad: Servicio y atención a la familia.

Mitos sobre la maternidad: Se considera la maternidad como un hecho natural, y se naturaliza también otras funciones domésticas que cumple la mujer propias a su condición femenina.

Roles y prácticas adscritas a la maternidad: Labores domésticas.

MENSAJE PUBLICITARIO 3:

Importadora Monge (Canal 7, 7/8/1999, 4:44 p.m.)

\section{Observaciones:}


El mensaje trasmite una recomendación sobre el regalo a la madre, en este caso es una cocina.

Texto: “¿Todavía no sabe que regalarle a mamá?” "Vamos a darle una luz, regálele una cocina de gas".

Imágenes: Electrodomésticos, ambiente de cocina, padre y dos hijos sentados en la mesa, mujer madre de pie atendiendo a la familia.

Estereotipo femenino: Mujer ama de casa.

Significados de la maternidad: Servicio, atención, entrega a la familia.

Mitos sobre la maternidad: La maternidad función "natural".

Roles y prácticas adscritas a la maternidad: Labores domésticas.

MENSAJE PUBLICITARIO 4:

Atlas Refrigeradoras Millenium (Canal 7, 7/8/1999, 5:08 p.m.)

\section{Observaciones:}

El comercial comienza con la imagen de una madre dejando una advertencia: hará cualquier cosa para tener una refrigeradora moderna.

Texto: "Mamá haría lo que fuera para no quedarse sin Su refrigeradora de lujo Atlas milenium".

Imágenes: Electrodomésticos, refrigeradora último modelo, mujer madre escribiendo la advertencia.

Estereotipo femenino: Mujer ama de casa.

Significados de la maternidad: Servicio, atención. 
Mitos sobre la maternidad: Maternidad función "natural”.

Roles y prácticas adscritas a la maternidad: Labores domésticas.

Mitos sobre la maternidad: No permite apreciar ninguno.

Roles y prácticas adscritas a la maternidad: No permite apreciar ninguno.

\section{ANÁLISIS Y COMENTARIOS ACERCA DE LOS MENSAJES PUBLICITARIOS TELEVISIVOS}

La televisión trasmite una diversidad de mensajes publicitarios imágenes, textos referidos a la maternidad, los cuales contienen una gran intencionalidad, y encuentran en este medio el vehículo ideal para la trasmisión, difusión y reforzamiento de creencias, valores, estereotipos y conductas.

Al realizar el análisis de los contenidos del material publicitario, se observa que la función maternal es objeto de un gran culto a través de homenajes y celebraciones, como el día la madre, sin embargo toda esta exaltación del ideal femenino posee una significación ambivalente que resulta complejo entender, ya que por una lado se magnifica la maternidad, se ensalza el amor maternal las virtudes de la madre; pero por otro, al considerarse la maternidad como parte de la naturaleza, ésta es desvalorizada y considerada poco importante, y se la condiciona a una situación de subordinación ligada al cuido de los hijos, de la familia y la realización de tareas domésticas. Los mensajes de la publicidad televisiva local giran alrededor del amor maternal, el amor incondicional de la madre a los hijos e hijas. Maternidad y amor son sinónimos, posee una alta valoración en la 
sociedad, a través de este valor, la sociedad mide el sacrificio, el esfuerzo, la entrega, la incondicionalidad de las madres. En nombre del amor se delega en la mujer todas las tareas de cuido a los demás y se posterga su realización personal.

La televisión dentro de los medios masivos de comunicación es uno de los mejores promotores del mito Mujer = Madre, y de un modelo femenino que identifica a la mujermadre con la mujer ama de casa, circunscrita al ámbito de su hogar y a un espacio físico que corresponde a la casa.

En general, los medios de comunicación juegan un papel muy importante para que los roles sociales se mantengan, enseñándole a la gente a creer que la diferencia sexual en cuanto a las funciones es biológica, apropiada y deseable para hombres y mujeres, para lo cual cumple la función de "convencer" de que resulta benéfico y equilibrado asumir el rol social que les corresponde.

\section{ANÁLISIS DE LOS ARTÍCULOS PERIODÍSTICOS}

Para efectos de este trabajo se pondrán de ejemplo tres artículos periodísticos, de una muestra total de 24 artículos, los cuales forman parte de la investigación.

\section{ARTÍCULO 1: \\ “Madre y esposa" (La República, 4/ 8/ 1993). \\ Según este artículo, ser madre y esposa tiene los siguientes significados:}


“...El ser esposa implica no solo cumplir con las tareas del hogar, atender al marido, educar a los hijos y ser buena madre; este rol tan importante para una mujer significa más que eso. Es a ella que le corresponde con su sabiduría de esposa guiar a su marido, ayudarlo a mejorar como persona por el ejercicio de las virtudes humanas, y si tiene fe, también de las virtudes sobrenaturales.

Ser madre significa en general estar entregada incondicionalmente a los demás sin esperar recompensa.

El papel de esposa para una mujer significa que el mejor servicio que una esposa pude prestar a su marido es ayudarle a ser un buen esposo, un buen padre, haciéndole tomar conciencia del papel que le corresponde...una mujer debe velar por que la imagen del padre no se deteriore y sea ensalzada ante los hijos y los demás..."

En este articulo se resume toda la carga ideológica de prescripciones normativas moralizantes y culpógenas, que limitan y asfixian a la mujer. A ella se le reclama y responsabiliza no sólo de la crianza y educación de los hijos, sino también del desempeño del marido como padre y esposo.

\section{ARTÍ́CULO 2:}

“Confíe en sí misma como madre". Nota de consejos para las madres (Revista

Perfil, agosto de 1994)

En este artículo se sugieren entre otros consejos para las madres, los siguientes:

“...Después del parto médicos y enfermeras le han dado innumerables consejos. A veces le parece emprender una tarea muy complicada... No tome demasiado en serio cuanto oiga decir en torno suyo, ni se deje impresionar por lo que dicen los expertos: no sienta el menor temor de fiarse de su propio sentido común.

La crianza de su hijo no será un asunto complicado si confía en su propio instinto materno..."

Esta concepción naturalista que mantiene el mito del instinto materno, sostiene que la madre posee un saber hacer instintivo que le permitirá entender mejor que nadie al hijo, y 
por lo tanto ella es irremplazable. Dicho instinto la guiará para encontrar siempre el camino adecuado en la relación con el hijo. Es infalible, ella siempre va a saber por instinto. Todo esto implica en la madre un monto de postergación personal. Se hace necesario apelar a la noción del instinto, porque esta caracterización da cierta ilusión de fuerte sustento, remite a la ilusión de estar inscritos en un orden necesario natural.

\section{ARTÍ́CULO 3:}

"Familia germen de amor y esperanza. Las madres dentro de la familia" ( $\mathrm{La}$ Nación, Suplemento Especial del Día de la Madre, 14/ 8/ 1994)

Con motivo del "Día de la Madre", se publica un suplemento especial en el cual se equipara la función maternal con el concepto de entrega y sacrificio, según puede apreciarse en la siguientes afirmaciones:

“...El aprendizaje de los conceptos de entrega, generosidad, laboriosidad, sacrificio, felicidad y amor se deriva de la madre... La madre es la que más contacto tiene con los hijos, y por naturaleza tiene una mayor capacidad para transmitir diversos valores...la maternidad ha dado una gran capacidad de amar..."

En este supuesto de naturalidad del vinculo madre-hijo se puede encontrar las raíces de desvalorización de la maternidad. Desde el momento que se supone que la mujer por el hecho de haber nacido con la capacidad biológica de reproducirse sabe como ser madre, no se le reconoce el complejo y trabajoso proceso de convertirse en madre. En este mismo artículo se continúa enfatizando lo siguiente:

“...la falta de ternura de la madre genera carencias en los niños y jóvenes que tratan de llenar con otras cosas como las drogas...." 
Afirmaciones como éstas, tienden a responsabilizar y culpabilizar a la madre con respecto la educación de los niños, al mismo tiempo que niega al hombre su participación responsable en estas funciones.

\section{ANÁLISIS Y COMENTARIOS ACERCA DE LOS ARTICULOS EN LA} PRENSA ESCRITA

En resumen, puede afirmarse con base en la evidencia encontrada, que en la prensa escrita se pueden apreciar las siguientes tendencias:

1. La prensa escrita atribuye a la maternidad significados de sacrificio, entrega, abnegación, generosidad. La práctica maternal está sustentada en estos valores que conforman para nuestra sociedad todo un "ideal maternal".

2. Los criterios normativos sobre la maternidad, hacen recaer la responsabilidad del bienestar del hijo sobre la mujer, y dan recetas para el comportamiento maternal. En los artículos publicados con relación al día de la madre, están presentes los mitos que nuestra sociedad ha construido alrededor de la maternidad como son el del "Instinto Materno" y el de "Mujer igual Madre".

3. Los artículos sobre la función maternal, analizados en el presente trabajo, coinciden en definir la maternidad como una función "natural" de la mujer, inherente a su condición femenina. De esta forma, se adscribe la maternidad como un fenómeno de la naturaleza y no de la cultura. 
4. El trato noticioso del abandono infantil, infanticidio por parte de la Prensa escrita no es el mismo cuando cometen estos delitos el padre o la madre. El peso de la sanción, la censura, la condena recae inflexible cuando la madre se aparta del comportamiento que la sociedad espera y exige de ella. El abandono materno y el infanticidio son delitos que en la prensa escrita tienen un gran impacto noticioso, lo que no ocurre cuando se informa sobre el abandono paterno.

5. Los discursos médicos, científicos y religiosos sobre la maternidad, se encuentran impregnados de una base instintivista, naturalista, la cual reduce la maternidad a una función de la naturaleza. La concepción tradicional de la paternidad, se está modificando y va dando lugar a una nueva menos estereotipada y más equitativa.

\section{CONCLUSIONES}

Los resultados de las investigaciones realizadas sobre maternidad y medios masivos de comunicación, permiten tomar conciencia de la poderosa influencia que ejercen los contenidos ideológicos de los mensajes, que a través de la televisión y la prensa escrita se trasmiten, en la concepción de la función maternal, en los significados que se le atribuyen a la maternidad, y en la socialización diferenciada por sexo.

Al descubrir la carga ideológica de los mensajes publicitarios, que se trasmiten a través de los medios masivos de comunicación sobre forma del ser madre, se debe realizar una labor de información para hacer conciencia sobre la necesidad de adoptar programas destinados a promover una justa valoración, una mayor equidad en la representación de la maternidad y la 
paternidad.

Así mismo la divulgación de los resultados de este trabajo deben estar encaminados a impulsar mecanismos de vigilancia respecto contenidos de mensajes televisivos, escritos, publicidad comercial, etc., que dañen la imagen de la mujer madre. Finalmente, los resultados encontrados se espera generen la realización de otros estudios en esta misma línea de investigación, así como investigaciones transculturales para poder realizar comparaciones entre los datos obtenidos...

\section{BIBLIOGRAFÍA}

Álvarez, Ana Teresa. 1987. "Proceso de socialización, roles sexuales". Actualidades en Psicología, 3: 23 (1987). San José: IIP, Universidad de Costa Rica.

Balán, Jorge. 1974. "Las historias de vida en Ciencias Sociales". Buenos Aires-Argentina: Ediciones Nueva Técnica.

Banditer, Elizabeth. 1981. ¿Existe el amor maternal? Barcelona: Editorial Paidós Pomairé.

Bermúdez, Marlen. 1982."El análisis de contenido. Procedimientos y aplicaciones”. Revista de Ciencias Sociales, No. 24 (1982).

Brenes, May. 1990. "Mujer y depresión". San José: Tesis de Licenciatura en Psicología, Universidad de Costa Rica.

Burín, Mabel. 1987. Estudios sobre la subjetividad femenina. Buenos Aires-Argentina: Editorial Latinoamericana.

Bustos, Olga. 1986. "Algunas consideraciones acerca de los papeles y estereotipos femeninos proyectados en los medios masivos de comunicación". Revista Universidad, No. 31 (UNAM, México).

. 1987. "Sexismo y Medios masivos de comunicación". Revista Casa del Tiempo, 8: 73 (Setiembre-Octubre 1987), (UNAM, México).

. 1988. "Socialización, papeles (roles) de género e imagen de la mujer en los medios masivos: Quienes perciben los estereotipos difundidos?". En: COLMEX, comp., La investigación sobre la mujer: informes en sus primeras versiones, Serie Documentos de Investigación, No. 1. México: COLMEX. 
Camacho, Rosalía. "La Maternidad como institución del Patriarcado: Representaciones y manifestaciones en obreras del sector textil". En:

Charles, Mercedes. 1993. "Construcción de la identidad de género en la comunicación masiva”. Revista Estudios de Género y Feminismo. México: Edit.orial Fontanamara, UNAM, México.

Desimone, Alexandra. 1992. "Lactancia y experiencia de maternidad". San José: Tesis de Licenciatura en Psicología, Universidad de Costa Rica.

Daskal, Ana. 1988. Identidad de mujer y maternidad. Buenos Aires-Argentina: Centro de Estudios de la Mujer, Universidad de Buenos Aires.

Fernández, Ana María. "Los Mitos Sociales de la Maternidad", No. 39. Buenos AiresArgentina: Centro de Estudios de la Mujer, Universidad de Buenos Aires.

García, Carola. 1993. Imagen femenina y vida cotidiana. México: Editorial Fontanamara, UNAM, México.

González, Mirta. 1988. Estudios de la Mujer, conocimiento y cambio. San José: EDUCA.

Heller, Ada. 1987. Sociología de la vida cotidiana. Barcelona: Editorial Península.

Lagarde, Marcela. 1993. Los cautiverios de las mujeres: madresposas, monjas, putas, presas y locas. México: UNAM, Colección Posgrado. . 1994. "Maternidad Feminismo y Democracia". Revista Repensar y Revisar la Maternidad. México: Grupo de Edición Popular.

Mattelard, Michele. 1986. "La Mujer y el orden de la crisis". Revista Los Medios de Comunicación en Tiempos de Crisis. México: Editorial Siglo XXI.

Madrigal, Johnny. 1990. Factores relacionados con el embarazo no deseado en Costa Rica. San José: Asociación Demográfica Costarricense.

Quiróz, Teresa. 1978. "La imagen de la mujer que proyectan los medios masivos de comunicación en Costa Rica". San José: Tesis Licenciatura en Sociología, Universidad de Costa Rica.

Robert, Jaime y Lobo, Isaura. 1995. “Televisión: ideología y socialización en la formación de la identidad personal y social del niño y la niña costarricenses". Actualidades en Psicología, 11:88 (1995). San José: IIP, Universidad de Costa Rica.

Solano, Mario. 1987. "El concepto de conciencia cotidiana". Actualidades en Psicología, 3:18 (1987). San José: IIP, Universidad de Costa Rica.

Stevees, Leslie. 1987. Feminist Theories and Media Studies. Critical Studies in Mass Cominication, 4: 2 (1987), USA.

Valladares, Blanca. 1995. "Los Mitos Sociales de la Maternidad". Revista de Ciencias Sociales, No 68 (Oct.ubre 1995).

1996. "Los Mitos Sociales de la Maternidad en la Prensa Escrita". Revista Casa de la Mujer, 5:8 (1996), Instituto de Estudios de la Mujer, Universidad Nacional, Heredia Costa Rica.

. 1997. "El Mito Social de la Maternidad y la realidad personal de un grupo de mujeres de la localidad de Palmares Prov. de Alajuela. Costa Rica". México: Tesis de Maestría en Psicología Social, Universidad Nacional Autónoma de México.

- 1998. "Los Mitos sociales de la maternidad. (Un estudio de casos)". Actualidades en Psicología, 17:98 (1998). San José: IIP, Universidad de Costa Rica. 
Vega, Isabel; Valladares, Blanca; Rodríguez, Ma. Elena; Escalante, Ana Cecilia y Salas, José Manuel , comp., "Lo Femenino y lo Masculino en la vida cotidiana. Jornadas de Investigación 1997”. San José: Vicerrectoría de Investigación, Instituto de Investigaciones Psicológicas, Universidad de Costa Rica.

Vega, Isabel. 1994. "Vida cotidiana y representaciones sociales en el estudio de la familia". Actualidades en Psicología, 10:83 (1994). San José: IIP, Universidad de Costa Rica.

Verón, Elisen. 1971. Ideología y comunicación de masas. Buenos Aires-Argentina: Ediciones Nueva Visión.

Videla, Mirta. 1973. Maternidad, Mito y Realidad. Buenos Aires-Argentina: Ediciones Nueva Visión. 